\title{
CORRIGENDUM
}

\section{Molecular correlates of anemia in primary myelofibrosis: a significant and independent association with U2AF1 mutations}

D Barraco, YC Elala, TL Lasho, KH Begna, N Gangat, C Finke, CA Hanson, RP Ketterling, A Pardanani and A Tefferi

Blood Cancer Journal (2016) 6, e416; doi:10.1038/bcj.2016.24; published online 6 May 2016

Correction to: Blood Cancer Journal (2016) 6, e415; doi:10.1038/ bcj.2016.22; published online 8 April 2016.
Following the publication of this article, the authors noted the following error: the Stat view statistical package is from Carey, NC. We apologize the readers for any inconvenience. 